\title{
An Intact Dorsomedial Hypothalamic Nucleus, but Not the Subzona Incerta or Reuniens Nucleus, Is Necessary for Short-Day Melatonin Signal-Induced Responses in Siberian Hamsters
}

\author{
Claudia Leitner Timothy J. Bartness \\ Department of Biology, Neurobiology and Behavior, and Brains and Behavior Programs, Georgia State University, \\ Atlanta, Ga., USA
}

\section{Key Words}

Lipolysis · Testicular regression $\cdot$ Photoperiod $\cdot$ Lesion

\begin{abstract}
Siberian hamsters provide a useful model to define mechanisms underlying obesity reversal as they naturally transition from their extreme seasonal obesity in long 'summer-like' days (LDs) to a leaner state in short 'winter-like' days (SDs). These day length changes are coded into durational melatonin (MEL) signals by the pineal gland resulting in stimulation of MEL receptors ( $\left.M E L_{1 a}-R s\right)$. MEL $L_{1 a}-R$ mRNA is colocalized centrally in sympathetic nervous system (SNS) outflow neurons comprising a chain of neurons that ultimately innervates white adipose tissue (WAT). Neural components in this circuit include the subzona incerta (subZl), dorsomedial hypothalamic nucleus (DMH) and thalamic reuniens nucleus (ReN). SD, long-duration MEL signals induce gonadal regression and increase WAT SNS drive triggering lipolysis and thereby reversing LD obesity. We attempted to block the reversal of SD MEL signal-induced obesity by making electrolytic or sham lesions of the subZI, ReN or DMH in LD-housed hamsters. To create SD-like, long-duration MEL signals, we injected MEL $3 \mathrm{~h}$ before lights out, thereby lengthening the
\end{abstract}

naturally occurring nocturnal duration of circulating MEL. ReN and subZI lesions did not block SD-like MEL signal-induced decreases in body, WAT, testicular masses or food intake; by contrast, DMH lesions blocked decreases in WAT and testicular mass. This nonresponsiveness was not due to lesion-induced inappropriate nocturnal LD MEL secretion that would have altered our creation of SD-like signals. Therefore, the DMH appears to participate in the control of both SD energy and reproductive responses, and joins the suprachiasmatic nucleus as sites necessary for SD responses in this species.

Copyright $\odot 2010$ S. Karger AG, Basel

\section{Introduction}

Obesity is the fastest growing health threat in the United States and many countries worldwide [1] due to its secondary health consequences such as stroke, cardiovascular disease, diabetes mellitus and certain types of cancer [1-3]. The specific mechanisms underlying the reversal of the obesity state are less well-studied than those involved in its development. Siberian hamsters provide a convenient model to study the reversal of obesity because

\section{KARGER}

Fax +4161306 1234

E-Mail karger@karger.ch

www.karger.com (c) 2010 S. Karger AG, Basel

Accessible online at: www.karger.com/nen
Timothy J. Bartness

Department of Biology, Georgia State University

24 Peachtree Ctr Ave NE

Atlanta, GA 30302-4010 (USA)

Tel. +1 404413 5334, Fax +1 404413 5301, E-Mail bartness@ gsu.edu 
this small rodent shows a marked seasonal obesity $(\sim 50 \%$ body fat) that increases in long 'summer-like' days (LDs), and is naturally reversed in short 'winter-like' days (SDs) in nature and the laboratory. In addition to the decreases in white adipose tissue (WAT), other seasonal responses occur in SDs including increases in brown adipose tissue thermogenesis, testicular regression and change to a white winter pelage [for reviews, see 4-6]. It is the peak nocturnal duration of pineal melatonin (MEL) secretion that faithfully codes the day length information into a neuroendocrine signal that triggers these responses [for a review, see 7]. This is clearly shown by eliciting these SD responses from $\mathrm{LD}$-housed pinealectomized Siberian hamsters that receive daily, timed, SD-like (long duration) subcutaneous MEL infusions $[8,9]$. Thus, we know the environmental stimulus (photoperiod change) and the critical parameter of MEL secretion (duration) profile for triggering seasonal responses in this species. Moreover, it is the stimulation of the only functional MEL receptor in Siberian hamsters, the melatonin $_{1 a}$ receptor $\left(\mathrm{MEL}_{1 \mathrm{a}} \mathrm{-} \mathrm{R}[10,11]\right)$ found on the sympathetic nervous system (SNS) outflow neurons comprising circuits that ultimate connect the brain to WAT [12] which, in turn, relays MEL signals into appropriate seasonal responses. When these neurons are activated, the SNS drive to WAT increases [13], and this, in turn, causes a release of the primary postganglionic SNS neurotransmitter, norepinephrine in WAT. Moreover, this initiates lipid mobilization [for reviews, see 14, 15]. There also are other sympatheticrelated responses that augment the $\mathrm{SD}$-induced increases in SNS drive to WAT to facilitate lipolysis including increased sensitivity to the lipolytic action of norepinephrine [16], perhaps via SD-triggered increases in the gene expression and subsequent synthesis of the protein for the major adrenergic adipocyte-associated membrane receptor in rodents, the $\beta_{3}$-adrenoreceptors [16].

Several forebrain areas exhibit significant numbers of WAT SNS outflow neurons bearing $\mathrm{MEL}_{1 \mathrm{a}} \mathrm{R}$ mRNA and these include the suprachiasmatic nucleus (SCN), dorsomedial nucleus of the hypothalamus (DMH), subzona incerta (subZI), paraventricular nucleus of the thalamus (PVT) and the nucleus reuniens (ReN [12]). We previously demonstrated that an intact SCN is necessary for the reception of SD MEL signals because bilateral lesions of the SCN in pinealectomized Siberian hamsters block the reception of SD-like, long duration, daily subcutaneous infusions of MEL, whereas intact hamsters respond by decreasing their body and lipid mass and regressing their gonads $[17,18]$ as they would if they were moved from LDs to SDs. The necessity of an intact SCN had been repeatedly demonstrated to block all responses to SD-like MEL signals in this species [17-19]. The necessity of an intact DMH for reception/transmission of SD MEL signals has been shown in a different hamster species, Syrian hamsters (Mesocricetus auratus). In pinealectomized Syrian hamsters bearing lesions of the $\mathrm{DMH}$, the ability of timed daily long-duration (SD-like) MEL signals to generate SD-like inhibition of the reproductive system is blocked [20]. The necessity of the PVT for the reception of MEL signals has been tested in Siberian hamsters, but does not appear to play a role in SD-induced decreases in body mass, food intake or torpor frequency [21]. The PVT also does not appear important for the reception of and response to SD MEL signals in Siberian hamsters [21].

Therefore, the purpose of the present experiment was to test whether the remaining brain sites that display prominent colocalization of $\mathrm{MEL}_{1 \mathrm{a}}$-mRNA with WAT SNS outflow neurons will respond to SD-like MEL signals and thus trigger SD-like responses in Siberian hamsters - specifically, the DMH, ReN and subZI. This was accomplished by challenging hamsters bearing lesions of each of these sites with SD-like, long-duration MEL signals generated by subcutaneous daily timed injections of MEL designed to lengthen the natural duration of LD pineal MEL secretion, thereby triggering SD responses, a method successfully used previously in this species [e.g., 22-24]. We used the timed MEL injection model in place of transferring animals from LDs to SDs for several reasons: (a) the SD-like responses are synchronized better than with the photoperiod change (unpubl. observations) and (b) in our experience, all animals exhibit SD-like responses when injected with MEL, whereas with photoperiod transfer, as many as $30 \%$ are nonresponsive to the photoperiod (unpubl. observations). We chose restricted electrolytic lesions to block the reception/transmission of SD-like MEL signals, rather than site-specific timed microinjections of an $\mathrm{MEL}_{1 \mathrm{a}}-\mathrm{R}$ antagonist at the targeted brain sites, because we are unaware of a specific, high-affinity $M E L_{1 a}-R$ antagonist with no agonist properties that have been tested in vivo (Leitner and Bartness, unpubl. observations). The results of this study demonstrated that an intact $\mathrm{DMH}$ was necessary to respond appropriately to SD-like MEL signals, as $\mathrm{DMH}$ lesions (DMHx) blocked SD-like decreases in WAT and serum testosterone concentrations, and partially blocked decreases in testes masses, whereas sham lesions did not do so. By contrast, an intact ReN or subZI was not necessary for reception/transmission of SD-like MEL signals. 


\section{Methods}

\section{Animal Housing}

All experiments were approved by the Georgia State University Institutional Animal Care and Use Committee (IACUC) and were in accordance with National Institutes of Health and United States Department of Agriculture guidelines. Siberian hamsters (Phodopus sungorus) were obtained from our breeding colony that was established in 1988 and its genealogy has been previously described [25]. The hamsters were housed in a vivarium where the temperature, relative humidity and photocycle were 20 $\pm 1.5^{\circ} \mathrm{C}, 50 \pm 5 \%$ and 16:8 h light:dark cycle (lights off at 10:30), respectively, for all experiments. Animals were given Purina lab chow 5001 (TestDiet, Brentwood, Mo., USA) and tap water ad libitum. Hamsters were weaned at 21 days postpartum and singly housed in polypropylene cages $(27.8 \times 17.5 \times 13.0 \mathrm{~cm})$ containing corn cob bedding (The Andersons, Maumee, Ohio, USA) and cotton nestlets (Ancare, Belmore, N.Y., USA) until used in the experiments.

\section{Electrolytic Lesions}

Adult $\sim 2.5$-month-old male Siberian hamsters $(\mathrm{n}=141)$ were used in these experiments. For electrolytic lesions, animals were anesthetized under isoflurane, hair was removed from the top of the head, an incision was made in the skin, and a hole was trephined in the skull to permit stereotaxic lowering of a stainless steel electrode insulated previously with Epoxylite ${ }^{\circledR}$ except at its cross-sectional tip [18]. Stereotaxic coordinates for the bilateral structures were: subZI $(\mathrm{n}=42)$ : anterior-posterior: $-0.3 \mathrm{~mm}$, medial-lateral: $\pm 0.75 \mathrm{~mm}$, dorsal-ventral: $-5.4 \mathrm{~mm}$ below the dura; $\mathrm{DMH}(\mathrm{n}=58)$ : anterior-posterior: $-1.1 \mathrm{~mm}$, medial-lateral: \pm 0.6 $\mathrm{mm}$, dorsal-ventral: $-5.8 \mathrm{~mm}$ below the dura, with the skull level. Stereotaxic coordinates for the midline structures were: $\operatorname{ReN}(\mathrm{n}=$ 41): anterior-posterior: $-0.1 \mathrm{~mm}$, medial-lateral: $0 \mathrm{~mm}$, dorsalventral: $-5.0 \mathrm{~mm}$ below the dura, with the skull level. For each lesion, $0.1 \mathrm{~mA}$ current was delivered for 6,8 and $13 \mathrm{~s}$ for the subZI, $\mathrm{ReN}$ and $\mathrm{DMH}$, respectively; current intensities were chosen based on pilot studies to produce maximal yet specific lesions. Animals were given a 10-day postsurgical recovery period.

\section{MEL Treatment}

Experiment 1: Effects of Lesions of the subZI, ReN and $\mathrm{DMH}$

In order to generate an SD-like, long-duration MEL signal, timed daily systemic injections of MEL were carried out $\sim 3$ h before lights off in these LD-housed, pineal intact hamsters to generate an exogenous MEL signal that summates with the shortduration endogenous LD MEL signal. This injection scheme results in a lengthening of the naturally occurring nocturnal MEL duration, thereby triggering SD responses by LD-housed Siberian hamsters [22-24]. The injections consisted of either the ethanolic saline control (1:9 parts) or MEL ( $5 \mu \mathrm{g}$ in $0.1 \mathrm{ml}$ ethanolic saline) prepared fresh daily from a stock solution of $500 \mu \mathrm{g} / \mathrm{ml}$ MEL in $100 \%$ ethanol [24]. Injections were given daily for 5 weeks, a time when body, fat and gonadal masses naturally are most rapidly decreasing in SDs [26-28]. Body mass and food intake were monitored weekly. WAT pads and testes were measured terminally as integrative indicators of adiposity and reproductive status, respectively (see below).

DMH Lesions and Photoperiodic Responses
Experiment 2: Effects of DMHx on Nocturnal Secretion of MEL

Because DMHx completely blocked the effects of SD-like MEL signals on body and fat mass, and partially blocked gonadal regression, it was necessary to test whether this inability to respond appropriately was due to the lesion blocking the reception/transmission of the SD-like MEL signals or whether the lesion altered the normal nocturnal secretion of pineal MEL such that the exogenously injected MEL did not summate properly with the naturally occurring nocturnal duration of MEL secretion in LDs. This was accomplished in a second experiment with male hamsters bearing DMHx of the same age/housing conditions as above ( $\mathrm{n}=$ 13). Orbital blood samples (see below) were obtained from Siberian hamsters bearing sham or DMHx for subsequent analysis of endogenous serum MEL concentrations at various times of the 16:8 h light:dark cycle (lights off at 19:00). Specifically samples were obtained $2 \mathrm{~h}$ before and 1, 3, 5, $7 \mathrm{~h}$ after lights off and $2 \mathrm{~h}$ after lights on, with blood collected from subsets of animals at every other time point, such that each subset had blood taken only 3 times as per IACUC regulations.

\section{Blood Serum Analysis}

After 5 weeks of these treatments, hamsters were anesthetized with isoflurane and orbital blood was taken for assay of serum testosterone (reproductive status), free fatty acids (FFA) and glycerol concentrations (lipolysis products). Blood ( $\sim 500 \mu \mathrm{l})$ was collected with heparinized glass capillary tubes, stored in glass culture tubes overnight at $4^{\circ} \mathrm{C}$ and centrifuged the next day at $4^{\circ} \mathrm{C}$ for $20 \mathrm{~min}$ at $2,000 \mathrm{rpm}$. Serum was removed and stored at $-80^{\circ} \mathrm{C}$ until analysis. Commercial glycerol (Sigma-Aldrich, St. Louis, Mo., USA), FFA (WAKO Chemicals, Richmond, Va., USA) and testosterone RIA (Diagnostic Systems Laboratories, Webster, Tex., USA) kits were used according to the manufacturer's instructions. For all testosterone assays, the overall correlation coefficient and intra-assay variability was 98.7 and $7.4 \%$, respectively. For experiment 2, a commercially available kit (Genway Biotech Inc., San Diego, Calif., USA) was used to determine serum MEL concentrations according to the manufacturer's instructions. The correlation coefficient for the MEL assay was $95.4 \%$.

\section{Perfusions and Lesion Verification}

After blood collection, animals were anesthetized with an overdose $(300 \mathrm{mg} / \mathrm{kg})$ of pentobarbital sodium and the right inguinal WAT (IWAT), bilateral retroperitoneal WAT and epididymal WAT (EWAT) depots and testes were removed, weighed, snap-frozen in liquid nitrogen and then stored at $-80^{\circ} \mathrm{C}$. The animals were then perfused transcardially between 04:00 and 09:00 with $\sim 125 \mathrm{ml}$ isotonic saline, followed by $\sim 125 \mathrm{ml}$ of $4 \%$ paraformaldehyde in $0.1 \mathrm{M}$ PBS solution ( $\mathrm{pH}$ 7.4). All brains were stored in $4 \%$ paraformaldehyde for $24 \mathrm{~h}$ and transferred to sucrose ( $30 \%$ with $0.1 \%$ sodium azide). Brains were then sectioned (80 $\mu \mathrm{m})$ in the coronal plane on a freezing microtome for lesion verification. Sections were mounted onto microscope slides (Superfrost, Fisher Scientific, Suwanee, Ga., USA) and dried overnight. The slides were then dehydrated and delipidated through a series of alcohol concentrations and xylene, stained with cresyl echt violet and finally coverslipped using Permount (Fisher Scientific) before microscopic examination of lesion location. To be included in the lesion group, the targeted nuclei had to achieve the criteria of destruction $>90 \%$ of the anterior-to-caudal extent, $>90 \%$ of the 
dorsal-to-ventral extent and $>90 \%$ of the medial-to-lateral extent for each nucleus. Siberian hamsters with insufficient damage or damage beyond the targeted nuclei were excluded from further analysis. Detailed descriptions of these relatively discrete, yet complete lesions are provided in the Results section.

\section{Statistical Analysis}

A two-way ANOVA analysis for percentage changes from baseline (see below) was conducted independently for each brain site for WAT pads, testes, serum constituents, body mass and food intake, with Bonferroni's post-hoc tests (GraphPad Prism version 4.00; GraphPad Software, San Diego, Calif., USA) done when appropriate. The percent change from the mean of the saline/shamtreated group served as baseline for WAT pads, testes and serum constituents, whereas within-animal comparisons were made for food intake and body mass comparing week 0 and terminal (week 5) values expressed as the percent change from baseline. Absolute values for all variables are shown in table 1 . Differences between means were considered significant if $\mathrm{p}<0.05$. Exact probabilities and test values were omitted for simplicity and clarity of presentation.

\section{Results}

Experiment 1: Effects of Lesions of the subZI, ReN and $D M H$

Lesion Verification

Electrolytic lesions were targeted for the ReN, subZI and $\mathrm{DMH}$ (fig. 1). Lesions aimed at the ReN often invaded neighboring areas including the anterior paraventricular nucleus, rhomboid nucleus and xiphoid nucleus of the thalamus. The difficulty in destroying the elongated structure of the subZI often induced damage to the zona incerta, subincertal nuclei and the incerto-hypothalamic area, although this damage was quite minimal. Damage to the $\mathrm{DMH}$ was mostly to the compact $\mathrm{DMH}$, but also included most of the diffuse $\mathrm{DMH}$ and was generally confined to anterior and medial portions of the $\mathrm{DMH}$. Due to the size of the $\mathrm{DMH}$, care was taken not do damage neighboring areas including the ventromedial and posterior hypothalamic nuclei; if damage occurred to these structures, the animals were not included in the analysis. Nine, 5 and 15 Siberian hamsters (subZI, ReN and $\mathrm{DMH}$, respectively) with incomplete lesions or misplaced lesions (spread beyond the areas mentioned above) were excluded from the analysis, resulting in 33, 36 and 43 animals for the subZI, ReN and DMH, respectively.

\section{Testes Mass and Serum Testosterone Concentrations}

None of the lesions affected testes mass in LD-like vehicle controls (fig. 2a). Lesions of the ReN and subZI did not block the gonadal regression seen in intact hamsters
Table 1. Absolute values of dependent variables

\begin{tabular}{|c|c|c|c|}
\hline & $\mathrm{ReN}$ & subZI & $\mathrm{DMH}$ \\
\hline FFA, mEq/l & $1.512 \pm 0.19$ & $1.475 \pm 0.17$ & $1.632 \pm 0.20$ \\
\hline Glycerol, $\mathrm{ng} / \mathrm{ml}$ & $1,493 \pm 144$ & $1,191 \pm 92.84$ & $1,314 \pm 52.34$ \\
\hline Testes, g & $0.91 \pm 0.05$ & $0.82 \pm 0.05$ & $0.9 \pm 0.03$ \\
\hline Testosterone, $\mathrm{ng} / \mathrm{ml}$ & $2.45 \pm 0.71$ & $2.07 \pm 0.44$ & $2.81 \pm 0.33$ \\
\hline \multicolumn{4}{|c|}{ Body mass (vs. week 0), g } \\
\hline Saline/sham & $37.20 \pm 2.21$ & $37.68 \pm 1.93$ & $39.02 \pm 1.20$ \\
\hline Saline/lesion & $36.37 \pm 1.36$ & $35.27 \pm 1.69$ & $34.97 \pm 1.34$ \\
\hline MEL/sham & $36.20 \pm 2.10$ & $37.36 \pm 1.67$ & $36.51 \pm 1.39$ \\
\hline MEL/lesion & $35.28 \pm 2.07$ & $36.12 \pm 0.84$ & $41.58 \pm 1.56$ \\
\hline \multicolumn{4}{|c|}{ Food intake (vs. week 0), g } \\
\hline Saline/sham & $31.13 \pm 1.0$ & $35.69 \pm 1.27$ & $36.38 \pm 0.63$ \\
\hline Saline/lesion & $35.14 \pm 2.39$ & $32.61 \pm 1.42$ & $35.39 \pm 0.75$ \\
\hline MEL/sham & $33.69 \pm 1.05$ & $32.60 \pm 1.67$ & $35.14 \pm 2.16$ \\
\hline MEL/lesion & $33.75 \pm 1.84$ & $38.16 \pm 2.54$ & $34.47 \pm 1.47$ \\
\hline \multicolumn{4}{|l|}{ WAT, g } \\
\hline EWAT & $0.90 \pm 0.08$ & $0.94 \pm 0.01$ & $0.99 \pm 0.04$ \\
\hline IWAT & $0.65 \pm 0.08$ & $0.62 \pm 0.07$ & $0.66 \pm 0.03$ \\
\hline RWAT & $0.17 \pm 0.03$ & $0.16 \pm 0.03$ & $0.18 \pm 0.01$ \\
\hline \multicolumn{4}{|c|}{ Melatonin (vs. $-2 \mathrm{~h}$ ), $\mathrm{pg} / \mathrm{ml}$} \\
\hline Sham & & & $36.4 \pm 6.3$ \\
\hline DMHx & & & $26.1 \pm 4.0$ \\
\hline
\end{tabular}

Mean \pm SEM absolute values from saline/sham- (unless otherwise noted) treated Siberian hamsters with lesions targeting the ReN, subZI and DMH to compliment remaining figures.

receiving 5 weeks of daily timed subcutaneous MEL injections delivered to generate SD-like MEL signals (fig. 2a). By contrast, DMHx nearly completely blocked the SD-like testicular regression in hamsters receiving the SD-like MEL signals compared with their sham lesion controls (fig. 2a; p < 0.05). Specifically, DMHx hamsters had paired testes masses of $\sim 720 \mathrm{mg}$ indicating that although testes mass was significantly decreased compared with controls, they likely were functional as we have found that paired testes masses of $<300 \mathrm{mg}$ in this species are associated with undetectable serum testosterone concentrations and are aspermatic (unpubl. observations). Indeed, contrary to Siberian hamsters bearing lesions of the ReN and subZI and receiving MEL, DMHx hamsters receiving MEL did not have decreased serum testosterone seen in MEL-injected animals with sham lesions (fig. 2b). Thus, although DMHx hamsters receiving SDlike MEL signals had minor decreases in paired testes mass, serum testosterone concentrations were not different from saline-treated DMHx or hamsters bearing sham DMHx (fig. 2b). 

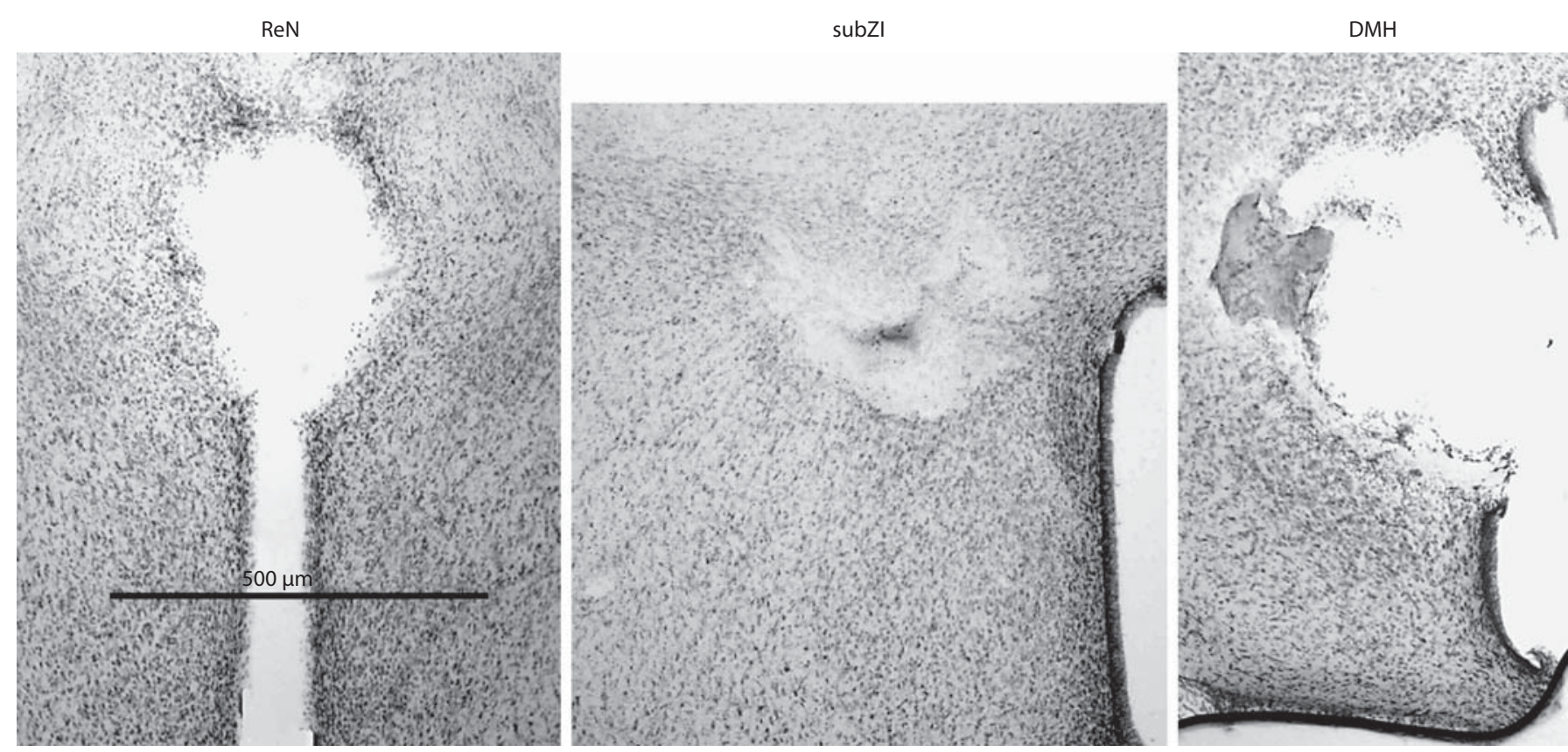

Fig. 1. Lesion verification. Photographic representation of lesion of the ReN, subZI and DMH in Siberian hamsters exposed to SD-like MEL signals for 5 weeks.

\section{Body Mass and Food Intake}

Lesions of the DMH, ReN or subZI did not block SD MEL signal-induced decreased body mass $(\mathrm{p}<0.05$; fig. 3a). Similarly, lesions of the subZI and ReN did not block the decreased food intake triggered by the SD-like MEL signals (fig. 3b), whereas MEL treatment in the $\mathrm{DMH}$ group did not result in decreased food intake (fig. 3b).

\section{WAT Mass}

Typically, substantial changes in body mass are reflected in changes in lipid mass in adult mammals. Here, SD-like MEL signals significantly decreased body mass in all groups ( $\mathrm{p}<0.05$; fig. $3 \mathrm{a}$ ). ReN and subZI lesions did not block the decrease in total dissected WAT mass (sum of IWAT, EWAT and retroperitoneal WAT; fig. 4) that occurred with MEL treatment in hamsters with sham lesions $(\mathrm{p}<0.05)$. Interestingly, lesions of the subZI decreased total WAT mass in saline-injected hamsters ( $\mathrm{p}<$ 0.05 ; fig. 4), a difference that also was reflected by significant decreases in the masses of each of the individual fat pads (data not shown). By contrast, DMHx blocked MEL-induced decreases in WAT mass $(\mathrm{p}<0.05$; fig. 4$)$ and this was reflected as decreases in all fat pads, but significantly only in the EWAT and IWAT depots (mean \pm
SEM: EWAT: DMHsham/saline: $0.99 \pm 0.04 \mathrm{~g}, \mathrm{DMHx} /$ saline: $0.94 \pm 0.07 \mathrm{~g}$, DMHsham/MEL: $0.52 \pm 0.06 \mathrm{~g}$, DMHx/MEL: $0.90 \pm 0.1 \mathrm{~g}$; IWAT: DMHsham/saline: $0.66 \pm 0.03 \mathrm{~g}, \mathrm{DMHx} /$ saline: $0.79 \pm 0.09 \mathrm{~g}$, DMHsham/ MEL: $0.45 \pm 0.04 \mathrm{~g}, \mathrm{DMHx} / \mathrm{MEL}: 0.69 \pm 0.08 \mathrm{~g}$ ).

\section{Serum FFA and Glycerol Concentrations}

SubZI lesions significantly decreased FFA and glycerol independent of the treatment group (MEL vs. saline, table 2; $\mathrm{p}<0.05$ ), but did not block SD-like MEL-induced decreases in glycerol. Lesions of the ReN and $\mathrm{DMH}$ also did not block SD-like MEL-induced decreases in glycerol, and lesions of the ReN did not block SD-like MEL-induced decreases in FFA (table 2).

\section{Experiment 2: Effects of DMHx on Nocturnal Secretion of MEL}

Because DMHx blocked SD MEL signal-triggered responses, it was possible that DMHx disrupted the duration and/or timing of the naturally occurring, LD nocturnal MEL signal such that the exogenous MEL injections did not summate with the endogenous MEL to create lengthened (SD-like) MEL signals. DMHx did not, however, appear to interfere with normal nocturnal MEL production (fig. 5). Absolute baseline levels as well as peak 


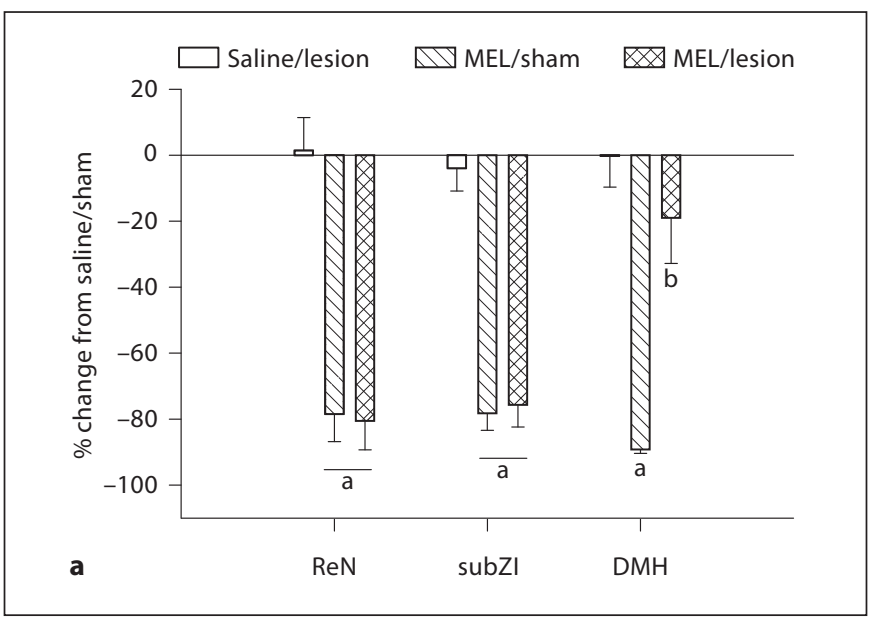

Fig. 2. Testicular response. a Mean \pm SEM percent change from control (saline-treated, sham-operated) of testes mass (g) in MELtreated Siberian hamsters bearing lesions at the ReN, subZI and DMH. b Mean \pm SEM percent change from control (saline-treated, sham-operated) of serum testosterone levels ( $\mathrm{ng} / \mathrm{ml}$ ) in MEL-

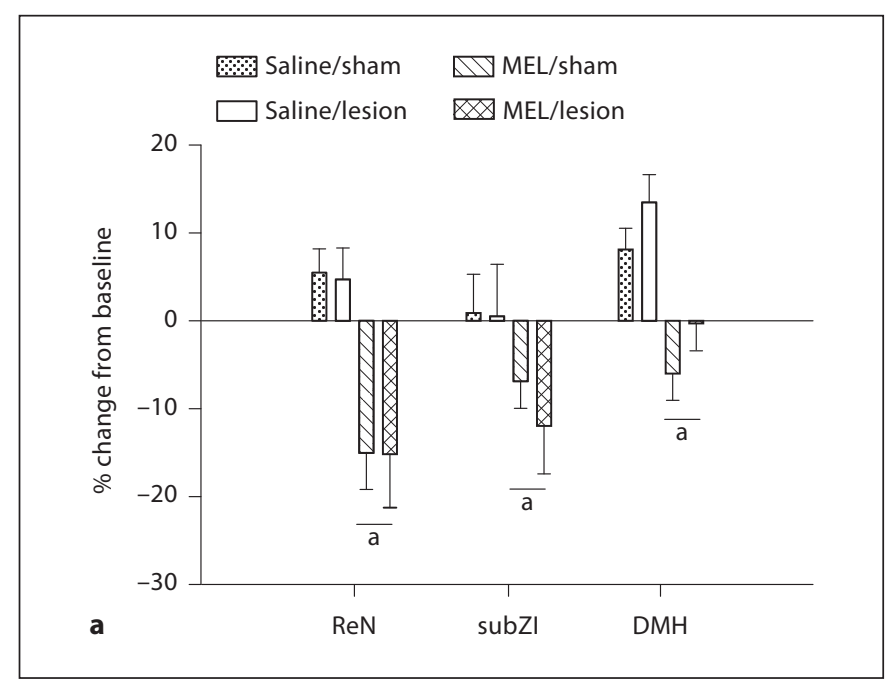

Fig. 3. Changes in body mass (a) and food intake (b). a Mean \pm SEM percent change of body mass after 5 weeks of MEL treatment in Siberian hamsters bearing lesions of the ReN, subZI and DMH or sham-operated animals. b Mean \pm SEM percent change of food intake after 5 weeks of MEL treatment in Siberian hamsters

and duration of nocturnal MEL secretion were indistinguishable from sham-operated controls. Specifically, serum MEL concentrations were significantly elevated in the dark phase 3,5 and $7 \mathrm{~h}$ (fig. $5, \mathrm{p}<0.05$ ) after lights off compared with measures taken in the light phase (i.e.,

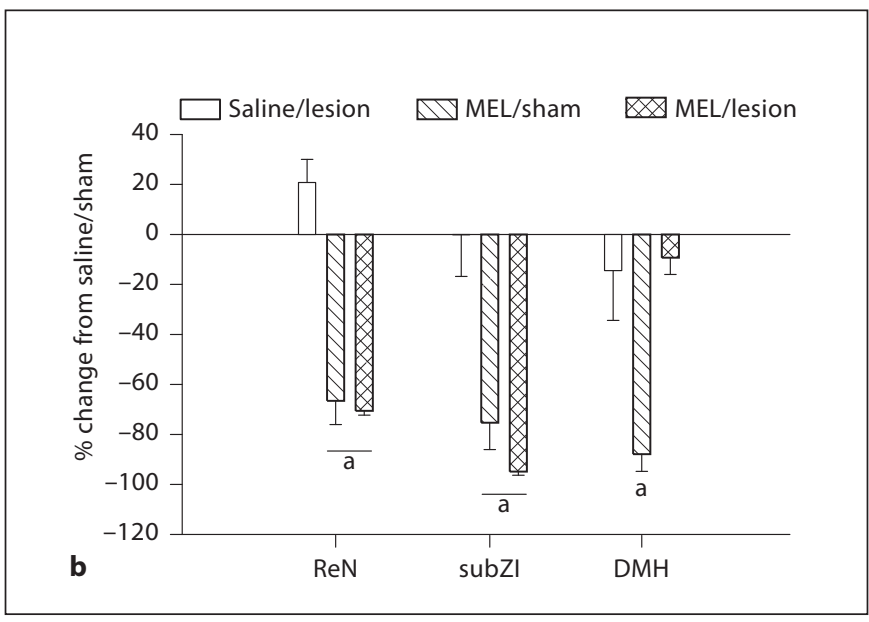

treated Siberian hamsters bearing lesions of the ReN, subZI and DMH. ${ }^{a} \mathrm{p}<0.05$ between saline and MEL treatment; ${ }^{\mathrm{b}} \mathrm{p}<0.05$ between MEL/lesion and all other groups. Number of animals: saline/sham, saline/lesion, MEL/sham, MEL/lesion, respectively: ReN n = 9, 10, 10, 7; subZI n = 9, 7, 10, 7; DMHx n = 7, 5, 11, 7 .

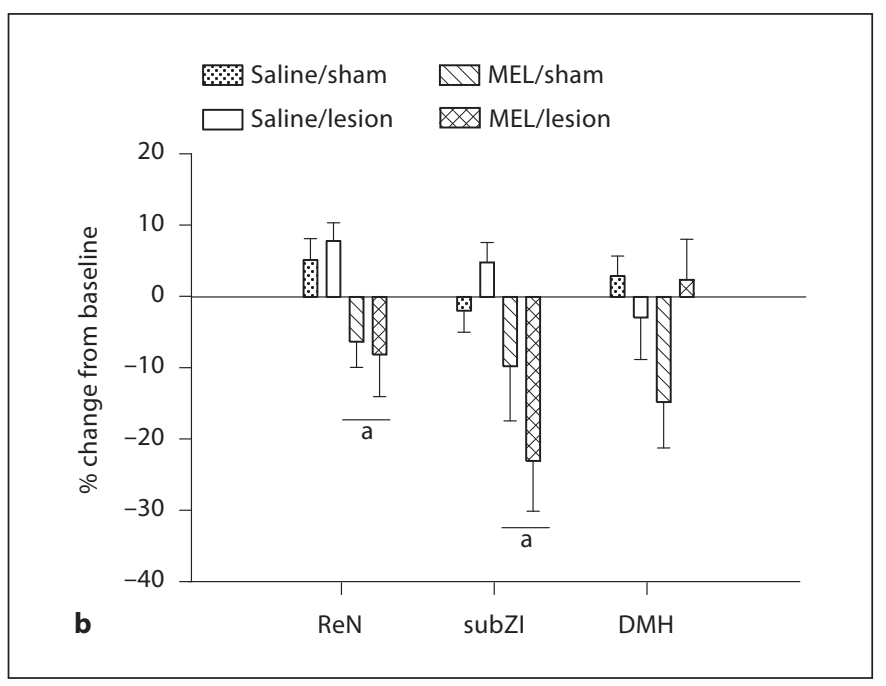

bearing lesions of the ReN, subZI and DMH or sham-operated animals. ${ }^{a} p<0.05$ between saline and MEL treatment. Number of animals: saline/sham, saline/lesion, MEL/sham, MEL/lesion, respectively: $\operatorname{ReN} n=9,10,10,7$; subZI $n=9,7,10,7 ;$ DMHx $n=$ $7,5,11,7$.

$2 \mathrm{~h}$ before lights off and $2 \mathrm{~h}$ after lights on). Serum MEL concentrations after $1 \mathrm{~h}$ of darkness approached significant increases $(p=0.07)$ compared to those of the light phase (fig. 5). 


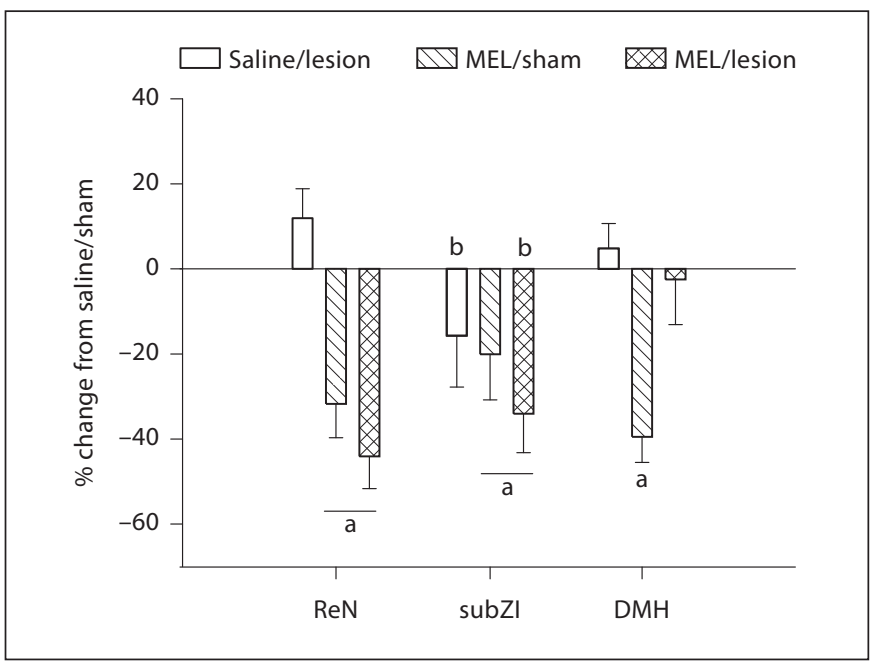

Fig. 4. Decrease in total dissected WAT. Mean \pm SEM percent change from controls (saline-treated, sham-operated) of fat pad mass ( $\mathrm{g}$ ) in Siberian hamsters bearing lesions of the ReN, subZI, and DMH. ${ }^{\mathrm{a}} \mathrm{p}<0.05$ between saline and MEL treatment; ${ }^{\mathrm{b}} \mathrm{p}<$ 0.05 between sham-operated animals and animals bearing lesions. Number of animals: saline/sham, saline/lesion, MEL/sham, MEL/lesion, respectively: $\operatorname{ReN} n=9,10,10,7$; subZI $n=9,7,10$, 7; DMHx n =7, 5, 11, 7 .

\section{Discussion}

We tested the necessity of the subZI, ReN and DMH in Siberian hamsters receiving 5 weeks of long-duration, SD-like MEL signals sufficient to trigger SD-like responses. We found that neither the ReN nor the subZI were necessary for any of the SD responses investigated here. Although the subZI was not necessary for SD responses, animals bearing these lesions had decreased WAT mass in both LDs and SDs and corresponding decreased circulating FFA and glycerol concentrations. By contrast, DMHx blocked SD-like MEL-induced decreases in fat pad mass and produced a significant, but small decrease in paired testes mass; however, this was accompanied by normal serum testosterone concentrations suggesting functional testes and thus functionally blocked SD-like gonadal responses. Moreover, this nonresponsiveness to SD-like MEL signals in hamsters bearing DMHx was not due to inappropriate nocturnal MEL secretion. Therefore, these latter data suggest that the $\mathrm{DMH}$ is involved in downstream mechanisms controlling both SD/MEL body fat and reproductive responses.

In Syrian hamsters, the importance of the DMH in receiving SD MEL signals was determined previously

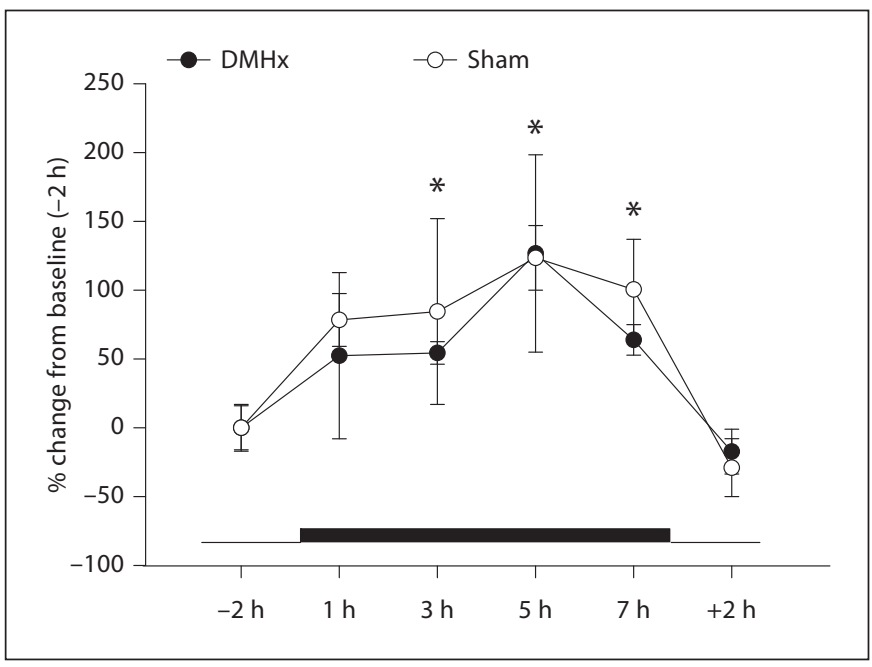

Fig. 5. Nocturnal MEL secretion in Siberian hamsters with DMHx. Mean \pm SEM percent change of MEL concentrations ( $\mathrm{pg} / \mathrm{ml})$ of Siberian hamsters with DMHx and sham-operated animals. The thick black bar represents the duration of the dark period vs. the thin bar, which represents the light phase. ${ }^{*} \mathrm{p}<0.05$ from baseline $(-2 \mathrm{~h})$. Number of animals: DMHx $\mathrm{n}=8$, sham $\mathrm{n}=5$.

Table 2. FFA and glycerol concentrations in Siberian hamsters bearing lesions of the ReN, subZI and DMH

\begin{tabular}{cccc}
\hline & Saline/lesion & MEL/sham & MEL/lesion \\
\hline FFA & & & \\
ReN & $-2.66 \pm 9.30$ & $-22.20 \pm 9.99^{*}$ & $-22.5 \pm 11.42^{*}$ \\
subZI & $-11.53 \pm 13.60^{\dagger}$ & $-19.12 \pm 11.60$ & $-32.58 \pm 8.54^{\dagger}$ \\
DMH & $-5.70 \pm 9.91$ & $-28.00 \pm 6.68$ & $-8.27 \pm 14.56$ \\
Glycerol & & & \\
ReN & $-17.3 \pm 12.08$ & $-37.40 \pm 5.23^{*}$ & $-30.1 \pm 7.50^{*}$ \\
subZI & $-30.09 \pm 10.50^{\dagger}$ & $-19.38 \pm 5.97^{*}$ & $-32.01 \pm 7.60^{\dagger, *}$ \\
DMH & $11.55 \pm 11.22$ & $-20.07 \pm 5.45^{*}$ & $-16.07 \pm 7.07^{*}$ \\
\hline
\end{tabular}

Mean \pm SEM percent change of FFA and glycerol after 5 weeks of MEL treatment in Siberian hamsters bearing lesions of the ReN, subZI and DMH from controls (saline/sham).

${ }^{*} \mathrm{p}<0.05$ between MEL and saline; ${ }^{\dagger} \mathrm{p}<0.05$ between lesion and sham animals.

[20]. Specifically, DMHx in pinealectomized Syrian hamsters blocked the ability of SD-like MEL signals given via the timed daily subcutaneous MEL infusion model to induce decreases in luteinizing hormone and testicular regression [20], without affecting SD-induced de- 
creases in serum prolactin concentrations. While the present study was underway, the necessity of the DMH for seasonal testicular regression in the Siberian hamster was suggested, but in data presented only in review form [29]. DMHx in LD-housed hamsters in that report produced an insignificant, but suggestive decrease in paired testes, EWAT and body mass [29], perhaps suggesting a partial maintenance role of the $\mathrm{DMH}$ in reproduction and energy balance in this species. Moreover, in SDs, DMHx blocked the SD-induced decrease in EWAT mass, produced a suggestive but not significant blockade of SD-triggered decreases in body mass, and produced a partial blockade of SD-triggered testicular regression (i.e., SD hamster DMHx paired testes mass was significantly greater than in SD sham DMHx), but less than that of LD sham DMHx hamsters [29]. These data are similar to the present data where we also found a partial decrease in paired testes size of DMHx given MEL injections, but not significantly lowered serum testosterone concentrations, suggesting the control of the hypothalamic-pituitary-gonadal axis and testicular testosterone secretion specifically were not affected by the SD MEL signals in animals bearing this lesion. We found a blockade of SD-like MEL signal-induced reduction in EWAT mass by DMHx (data not shown) that also was reflected in total dissected WAT, similar to the DMHx blockade of SD-triggered EWAT mass in their study [29]; this suggests that the DMH is involved in the control of EWAT lipid stores. There appears to be a lack of an effect of DMHx on body mass; however, after 5 weeks of SD MEL treatment (fig. 3a), there is a suggestive, nonsignificant increase in body mass after DMHx in non-MEL-treated control animals. To summarize these findings, the DMH appears to play a critical role in transmitting SD signals to other areas of the brain and periphery downstream of $\mathrm{MEL}_{1 \mathrm{a}}-\mathrm{Rs}$ located there in Siberian hamsters [12]. It is not, however, involved in the generation of SD MEL signals, as the levels and pattern of nocturnal serum MEL concentrations did not differ from controls. MEL binding sites in the compact DMH overlap with the expression of androgen receptors, at least in Syrian hamsters [20], thereby possibly modulating feedback to gonadotropin-releasing hormone neurons essential for seasonal reproduction [for a review, see 30]. The DMH also expresses other types of neurons, including products of the RFamide-related peptide gene (RFrp) whose expression appears MEL dependent [31], although it remains unclear if MEL directly or indirectly exerts its effects on RFrp-positive neurons. RFrp does appear to have effects on the reproductive system as it inhibits sexual behavior and luteinizing hormone secretion in laboratory rats [32, 33] as well as gonadotropin-releasing hormone synthesis and release in birds [34]. In terms of the role of the DMH in body and fat mass in the present study and previous work in this species [29], this is not completely surprising, as the DMH has been strongly implicated in energy balance and body and lipid mass control in rodents via studies of DMHx for almost 40 years [35; for a review, see 36].

The present data suggest that the $\mathrm{DMH}$ be added to the SCN as sites necessary for SD responses in this species, as we previously demonstrated that bilateral lesions of the SCN block the reception of SD-like MEL infusions, whereas intact hamsters respond by decreasing lipid mass and regress their gonads [17-19]. Regarding sufficiency of these areas for receiving/transmitting MEL signals, constant-release MEL implants as well as SD-like MEL signals in the SCN, PVT, ReN and DMH induce gonadal regression and decreases in body and some fat pad mass $[37,38]$, but thus far, only the SCN has been suggested as being necessary for these responses $[17,18,21]$. Initial reports also included the ReN, but not the PVT, as a necessary site for photoperiod-driven reductions in body mass, but not gonadal regression and torpor expression [21]. More specifically, the body mass of Siberian hamsters housed in SDs for 22 weeks bearing ReN lesions exceeded that of all control animals including the normal elevated body masses of intact LD controls versus their SD intact control counterparts [21]. We only tested SD-like conditions (long-duration MEL signals) for 5 weeks here, but with 22 weeks of SD exposure in the previous study [21], hamsters would be well on their way toward recrudescence of their body and lipid masses as well as the reversal of gonadal regression [39], perhaps accounting for the discrepancy between that study [21] and the present one.

There are, however, also other sites where MEL exerts its effects to control some seasonal responses. The pars tuberalis is a nonbrain, pituitary-associated area that has high concentrations of MEL binding sites in many species including Siberian hamsters $[40,41]$. The pars tuberalis and its effects on season reproduction are undeniable and, moreover, recently, its role in reproduction is more deeply understood playing a specific role in seasonal transitions in many bird and mammal species. Specifically, the pars tuberalis may signal photoperiod (MEL) changes to tanycytes located in the ependymal layer of the third ventricle where they can alter the ability of triiodothyronine $\left(\mathrm{T}_{3}\right)$, through changes in deiodinase enzymes, to increase $\mathrm{T}_{3}$ and restrict it to the hypo- 
thalamus. This, in turn, can affect reproductive and other seasonal responses, perhaps including changes in body mass/fat [42]. It is unclear how this system, or whether this system, interacts with the proven MEL receptors colocalized on the SNS outflow neurons to WAT and their clear role in mobilizing lipid stores from these fat pads in SDs $[12,13,16]$. This possible role of pars tuberalis-hypothalamic $\mathrm{T}_{3}$ signaling in body mass/fat decreases in SD exposed Siberian hamsters is not without challenge, with no change in thyrotropin-releasing hormone mRNA occurring in SDs [43]. It is clear, however, that direct restricted application of MEL to selected brain sites designed to simulate SD-like MEL signals at that site only elicits SD-like gonadal regression (SCN, subZI, SMH, ReN, PVT) and decreases in body and fat mass (SCN, subZI, SMH, ReN). This suggests that the involvement of the pars tuberalis is not necessary and perhaps even involvement of $\mathrm{T}_{3}$ signaling is not necessary [38]. Moreover, these data suggest the presence of a distributed system of MEL-responsive sites governing $\mathrm{SD}$ responses, at least in this species.

The subZI was not shown to be necessary for SD-like responses engendered by SD MEL signals here. The subZI is a 'new' structure, not appearing specifically in any rodent atlas, but is a distinct cell group that is not part of the zona incerta proper, nor an explicit extension of the $\mathrm{PVH}$, nor apparently equivalent to the incerto-hypothalamic area [44] and can be identified in laboratory mice and rats, as well as Syrian (unpubl. observations) and Siberian hamsters as shown in our previous work [12, 4549]. One of the few characteristics known about the subZI is that it is part of the SNS outflow to brown adipose tissue and WAT and, moreover, their sympathetic outflow neurons possess high concentrations of melanocortin 4 receptor mRNA $[48,49]$. Not surprisingly, stimulation of this site with melanotan II (a melanocortin 3 and 4 receptor agonist) stimulates brown adipose tissue thermogenesis [Vaughan and Bartness, in preparation]. An intact subZI does not seem necessary for the responses to SDlike MEL signals as lesions of the subZI induced a lipolytic state characterized by decreased WAT and decreased serum glycerol and FFAs regardless of whether they received MEL injections in the present experiment.

In the present experiment, we consistently found a MEL-induced decrease in FFA and/or glycerol. The decrease in serum FFA and glycerol concentrations in relation to decreased WAT mass seems discrepant as decreased WAT mass typically indicates increased lipid mobilization. Given that the WAT pads decreased by 40\% at this time, which is close to natural SD maximal WAT mass losses [16], active lipolysis likely occurred before our measures. Indeed, we tested for phosphorylation of two key proteins in WAT lipolytic responses, perilipin A and hormone-sensitive lipase, and also did not find an increase in these measures in the present animals at 5 weeks of treatment (data not shown), again indicating that the increases in lipolysis triggered by SDs with the associated increases in sympathetic drive to WAT (i.e., norepinephrine turnover [13]) had already occurred. These possibilities also likely explain the lack of an increase or decrease in these lipolytic products that often is seen with other lipid-mobilizing stimuli such as food deprivation and/or cold exposure [47, 50, 51].

In conclusion, we previously identified central sites with high populations of neurons that possess $M E L_{1 a}-R$ mRNA and that are part of the sympathetic outflow from brain to WAT ([12]; SCN, subZI, DMH, ReN and PVT). Site-specific stimulation of these brain areas with SD-like MEL signals induced testicular regression, decreases in body and fat pad mass, increased lipolysis and decreased food intake [52], arguing in favor of a distributed system involved in MEL-induced SD seasonal changes. Here we investigated the necessity of the ReN, subZI and $\mathrm{DMH}$, but not the SCN as we previously demonstrated that the SCN is necessary for SD responses in this species [17-19]. Electrolytic lesions of the ReN and subZI did not block the effects of SD-like MEL signals on body, WAT pad and testicular masses nor food intake. SD-like MEL signalinduced testicular regression, serum testosterone and decreases in WAT mass were blocked by DMHx in Siberian hamsters. This latter nonresponsiveness to SD-like MEL signals was not due to inappropriate nocturnal MEL secretion, suggesting DMH involvement in downstream mechanisms regulating both SD reproductive and body fat responses.

\section{Acknowledgments}

The authors thank Mary Karom for help measuring testosterone. In addition, we thank Dr. Brett Teubner for helpful comments during this project and Daniel Vizcaino for help during inconvenient working hours with this nocturnal species. We thank Dr. Michael Hastings for suggesting the last experiment. This work was funded, in part, by the National Institute of Health R37 DK35254 to T.J.B. 


\section{References}

$\checkmark 1$ Flegal KM: Epidemiologic aspects of over- 16 Bowers RR, Gettys TW, Prpic V, Harris RBS, weight and obesity in the United States. Physiol Behav 2005;86:599-602.

2 Satcher D: Overweight and obesity threaten U.S. health gains. www surgeongeneral gov/ topics/obesity.

3 Ogden CL, Carroll MD, Curtin LR, McDowell MA, Tabak CJ, Flegal KM: Prevalence of overweight and obesity in the United States, 1999-2004. JAMA 2006;295:1549-1555.

4 Bartness TJ, Wade GN: Photoperiodic control of seasonal body weight cycles in hamsters. Neurosci Biobehav Rev 1985;9:599612.

5 Mercer JG: Regulation of appetite and body weight in seasonal mammals. Comp Biochem Physiol C Pharmacol Toxicol Endocrinol 1998;119:295-303.

6 Prendergast BJ, Nelson RJ, Zucker I: Mammalian seasonal rhythms: behavior and neuroendocrine substrates; in Pfaff DW (ed): Hormones, Brain and Behavior. San Diego, Academic Press, 2002, pp 93-156.

-7 Bartness TJ, Powers JB, Hastings MH, Bittman EL, Goldman BD: The timed infusion paradigm for melatonin delivery: what has it taught us about the melatonin signal, its reception, and the photoperiodic control of seasonal responses? J Pineal Res 1993;15: 161-190.

8 Bartness TJ, Goldman BD: Peak duration of serum melatonin and short day responses in adult Siberian hamsters. Am J Physiol 1988; 255:R812-R822.

$\rightarrow 9$ Elliott JA, Bartness TJ, Goldman BD: Effect of melatonin infusion duration and frequency on gonad, lipid and body mass in pinealectomized male Siberian hamsters. J Biol Rhythms 1989;4:439-455.

10 Weaver DR, Rivkees SA, Reppert SM: Localization and characterization of melatonin receptors in rodent brain by in vitro autoradiography. J Neurosci 1989;9:2581-2590.

$\checkmark 11$ Weaver DR, Liu C, Reppert SM: Nature's knockout: the $\mathrm{Mel}_{1 \mathrm{~b}}$ receptor is not necessary for reproductive and circadian responses to melatonin in Siberian hamsters. Mol Endocrinol 1996;10:1478-1487.

12 Song CK, Bartness TJ: CNS sympathetic outflow neurons to white fat that express melatonin receptors may mediate seasonal adiposity. Am J Physiol 2001;281:R666-R672.

13 Youngstrom TG, Bartness TJ: Catecholaminergic innervation of white adipose tissue in the Siberian hamster. Am J Physiol 1995;268:R744-R751.

14 Bartness TJ, Song CK: Sympathetic and sensory innervation of white adipose tissue. J Lipid Res 2007;48:1655-1672.

15 Dodt C, Lonnroth P, Wellhoner JP, Fehm HL, Elam M: Sympathetic control of white adipose tissue in lean and obese humans. Acta Physiol Scand 2003;177:351-357. Bartness TJ: Short photoperiod exposure increases adipocyte sensitivity to noradrenergic stimulation in Siberian hamsters. Am J

17 Song CK, Bartness TJ: The effects of anterior hypothalamic lesions on short-day responses in Siberian hamsters given timed melatonin infusions. J Biol Rhythms 1996;11:14-26.

18 Bartness TJ, Goldman BD, Bittman EL: SCN lesions block responses to systemic melatonin infusions in Siberian hamsters. Am J Physiol 1991;260:R102-R112.

-19 Song CK, Bartness TJ: Dorsocaudal SCN microknife-cuts do not block short day responses in Siberian hamsters given melatonin infusions. Brain Res Bull 1998;45: 239-246.

20 Maywood E, Bittman EL, Hastings MH: Lesions of the melatonin- and androgen-responsive tissue of the dorsomedial nucleus of the hypothalamus block the gonadal response of male Syrian hamsters to programmed infusions of melatonin. Biol Reprod 1996;54:470-477.

21 Purvis CC, Duncan MJ: Discrete thalamic lesions attenuate winter adaptations and increase body weight. Am J Physiol 1997; 273:R226-R235.

22 Duncan MJ, Goldman BD, Di Pinto MN, Stetson MH: Testicular function and pelage color have different critical daylengths in the Djungarian hamster, Phodopus sungorus sungorus. Endocrinology 1985;116:424-430.

23 Puchalski W, Kliman R, Lynch GR: Differential effects of short day pretreatment on melatonin-induced adjustments in Djungarian hamsters. Life Sci 1988;43:1005-1012.

24 Bartness TJ, Wade GN: Body weight, food intake and energy regulation in exercising and melatonin-treated Siberian hamsters (Phodopus sungorus sungorus). Physiol Behav 1985;35:805-808.

25 Bowers RR, Festuccia WTL, Song CK, Shi H, Migliorini RH, Bartness TJ: Sympathetic innervation of white adipose tissue and its regulation of fat cell number. Am J Physiol 2004; 286:R1167-R1175.

26 Hoffmann K: The influence of photoperiod and melatonin on testis size, body weight, and pelage colour in the Djungarian hamster (Phodopus sungorus). J Comp Physiol 1973; 85:267-282.

27 Steinlechner S, Heldmaier G, Becker H: The seasonal cycle of body weight in the Djungarian hamster: photoperiodic control and the influence of starvation and melatonin. Oecologia 1983;60:401-405.

28 Wade GN, Bartness TJ: Effects of photoperiod and gonadectomy on food intake, body weight and body composition in Siberian hamsters. Am J Physiol 1984;246:R26-R30. Physiol 2005;288:R1354-R1360.
29 Ebling FJ, Barrett P: The regulation of seasonal changes in food intake and body weight. J Neuroendocrinol 2008;20:827-833.

30 Revel FG, Masson-Pevet M, Pevet P, Mikkelsen JD, Simonneaux V: Melatonin controls seasonal breeding by a network of hypothalamic targets. Neuroendocrinology 2009;90:1-14.

- 31 Revel FG, Saboureau M, Pevet P, Simonneaux V, Mikkelsen JD: RFamide-related peptide gene is a melatonin-driven photoperiodic gene. Endocrinology 2008;149:902912.

32 Johnson MA, Tsutsui K, Fraley GS: Rat RFamide-related peptide- 3 stimulates GH secretion, inhibits LH secretion, and has variable effects on sex behavior in the adult male rat. Horm Behav 2007;51:171-180.

-33 Kriegsfeld LJ, Mei DF, Bentley GE, Ubuka T, Mason AO, Inoue K, Ukena K, Tsutsui K, Silver R: Identification and characterization of a gonadotropin-inhibitory system in the brains of mammals. Proc Natl Acad Sci USA 2006;103:2410-2415.

- 34 Tsutsui K, Saigoh E, Ukena K, Teranishi H, Fujisawa Y, Kikuchi M, Ishii S, Sharp PJ: A novel avian hypothalamic peptide inhibiting gonadotropin release. Biochem Biophys Res Commun 2000;275:661-667.

35 Bernardis LL, Goldman JK, Chlouverakis C, Frohman LA: Six-month follow-up in weanling rats with ventromedial and dorsomedial hypothalamic lesions: somatic, endocrine, and metabolic changes. J Neurosci Res 1975; 1:95-108.

36 Bellinger LL, Bernardis LL: The dorsomedial hypothalamic nucleus and its role in ingestive behavior and body weight regulation: lessons learned from lesioning studies. Physiol Behav 2002;76:431-442.

37 Freeman DA, Zucker I: Refractoriness to melatonin occurs independently at multiple brain sites in Siberian hamsters. Proc Natl Acad Sci USA 2001;98:6447-6452.

38 Leitner C, Bartness TJ: Distributed forebrain sites mediate melatonin-induced short-day responses in Siberian hamsters. Endocrinology 2010;151:3133-3140.

39 Gorman MR, Zucker I: Seasonal adaptations of Siberian hamsters. II. Pattern of change in daylength controls annual testicular and body weight rhythms. Biol Reprod 1995;53: 116-125.

40 Weaver DR, Provencio I, Carlson LL, Reppert SM: Melatonin receptors and signal transduction in photorefractory Siberian hamsters (Phodopus sungorus). Endocrinology 1991;128:1086-1092.

41 Duncan MJ: Photoperiodic effects on puberty and specific 2- $\left[{ }^{125} \mathrm{I}\right]$ iodomelatonin binding sites in Siberian hamsters. Brain Res 1994;640:316-321. 
-42 Barrett P, Ebling FJ, Schuhler S, Wilson D, Ross AW, Warner A, Jethwa P, Boelen A, Visser TJ, Ozanne DM, Archer ZA, Mercer JG, Morgan PJ: Hypothalamic thyroid hormone catabolism acts as a gatekeeper for the seasonal control of body weight and reproduction. Endocrinology 2007; 148:36083617.

-43 Ebling FJ, Wilson D, Wood J, Hughes D, Mercer JG, Morgan PJ, Barrett P: The thyrotropin-releasing hormone secretory system in the hypothalamus of the Siberian hamster in long and short photoperiods. J Neuroendocrinol 2008;20:576-586.

44 Sita LV, Elias CF, Bittencourt JC: Connectivity pattern suggests that incerto-hypothalamic area belongs to the medial hypothalamic system. Neuroscience 2007;148:949969.
5 Bamshad M, Aoki VT, Adkison MG, Warren WS, Bartness TJ: Central nervous system origins of the sympathetic nervous system outflow to white adipose tissue. Am J Physiol 1998;275:R291-R299.

46 Bamshad M, Song CK, Bartness TJ: CNS origins of the sympathetic nervous system outflow to brown adipose tissue. Am J Physiol 1999;276:R1569-R1578.

47 Leitner C, Bartness TJ: Acute brown adipose tissue temperature response to cold in monosodium glutamate-treated Siberian hamsters. Brain Res 2009;1292:38-51.

48 Song CK, Vaughan CH, Keen-Rhinehart E, Harris RB, Richard D, Bartness TJ: Melanocortin-4 receptor mRNA expressed in sympathetic outflow neurons to brown adipose tissue: neuroanatomical and functional evidence. Am J Physiol 2008;295:R417-R428.
49 Song CK, Jackson RM, Harris RB, Richard D, Bartness TJ: Melanocortin-4 receptor mRNA is expressed in sympathetic nervous system outflow neurons to white adipose tissue. Am J Physiol Regul Integr Comp Physiol 2005;289:R1467-R1476.

50 Leitner C, Bartness TJ: Food deprivation-induced changes in body fat mobilization after neonatal monosodium glutamate treatment. Am J Physiol 2008;294:R775-R783.

51 Brito NA, Brito MN, Bartness TJ: Differential sympathetic drive to adipose tissues after food deprivation, cold exposure or glucoprivation. Am J Physiol Regul Integr Comp Physiol 2008;294:R1445-R1452.

52 Leitner C, Bartness TJ: Distributed forebrain sites mediate melatonin-induced short day responses in Siberian hamsters. Endocrinology 2010;151:3133-3140. 